\title{
Ortho-Para Catalysis in Liquid-Hydrogen Production ${ }^{1}$
}

\author{
D. H. Weitzel, W. V. Loebenstein, J. W. Draper, and O. E. Park
}

A series of selected or specially prepared catalysts were studied for their ability to accelerate the ortho to para conversion of hydrogen. The results of this study are presented, and the performance of various catalysts are compared with that of chromic oxide on alumina pellets. An outstanding catalyst, unsupported hydrous ferric oxide granules, was selected for further study and used in the liquefiers of the National Bureau of Standards Cryogenic Engineering Laboratory. One and one-half liters of this catalyst has now been used to convert more than 100,000 liters of liquid hydrogen to 90 to 95 percent para at an average rate of about 235 liters of liquid per hour. There is to date no evidence of decrease in efficiency with continued use.

\section{Introduction}

Freshly liquefied hydrogen that has not been catalyzed consists of a 3-to-1 ortho-para mixture. There is a slow but definite change in the mixture on standing, which complicates the problem of keeping the liquid for any great length of time. The exothermic heat of conversion of ortho- to parahydrogen at $20^{\circ} \mathrm{K}$ is about 254 calories per mole, whereas the endothermic heat of vaporization of liquid hydrogen is 216 calories per mole [1]. ${ }^{2}$ As a result of this slow change, a thermally isolated tank of liquid hydrogen prepared without conversion to the para form will lose about 18 percent of its volume during the first day of storage. In the absence of this internal evolution of heat, the heat transfer to a well-insulated Dewar may result in a loss of less than 1 percent per day.

The obvious solution of the above difficulty is the conversion to the para form either in the gas phase before liquefaction or in the liquid phase immediately after liquefaction, but in any case before delivery to the storage Dewar.

\subsection{Background}

Farkas and Sachsse [2] observed the catalytic effect of the paramagnetic molecule of oxygen in the gas phase on the conversion of parahydrogen to normal hydrogen. They also showed that the diamagnetic gases nitrogen, nitrous oxide, carbon dioxide, ammonia, hydriodic acid, sulfur dioxide, and iron pentacarbonyl caused no conversion, whereas the effects of the paramagnetic gases, nitric oxide and nitrogen dioxide, were similar to that of oxygen. The associated molecule $\mathrm{N}_{2} \mathrm{O}_{4}$ was ineffective.

Bonhoeffer and Harteck [3] were the first to make use of heterogeneous catalysis to establish ortho-para equilibrium. They used charcoal at liquid-air temperatures and were able to establish equilibrium quickly when normal hydrogen was passed over the catalyst. However, when parahydrogen was

1 This work was supported by the U. S. Atomic Energy Commission.

2 Figures in brackets indicate the literature references at the end of this paper. passed over charcoal at room temperature, no conversion took place [4].

Taylor and collaborators $[5,6]$ studied the catalytic activity of the metallic oxides and found that the paramagnetic substances chromic oxide, cerium oxide, and neodymium oxide brought about rapid conversion, whereas zinc oxide, lanthanum oxide, and vanadium pentoxide, having low or negligible paramagnetism, showed low or negligible conversion efficiencies. They conclude that the magnetic character of the surface of the catalyst is a controlling factor and may account for their earlier success with metallic nickel, as well as for the results of Emmett and Harkness [7] with Van der Waal's adsorption on iron synthetic ammonia catalysts.

\subsection{Chromic Oxide Catalyst}

Grilly [8] made use of commercially available chromic oxide on alumina for both gas and liquid phase conversion, his object being improvement in the keeping quality of the liquid produced. $\mathrm{He}$ successfully modified a liquefier so as to operate at 25 liters per hour for regular production of 85-percent para liquid.

Essentially pure (95 to 97 percent) parahydrogen was first produced in quantity at the National Bureau of Standards Cryogenic Engineering Laboratory in 1953 [9]. The catalyst was placed in the bottom of the liquefier reservoir. Liquid hydrogen from the expansion valve filtered through the catalyst before reaching the transfer siphon for delivery to the storage Dewar. Due to the urgency of the project, the chromic oxide catalyst, which had proved effective in Grilly's work, was used. It consisted of $1 / 8$-in. by $1 / 8$-in. pellets of approximately 20-percent chromic oxide on alumina.

About 65 liters of this catalyst resulted in conversion to 95 to 97 percent parahydrogen when the production was about 240 liters of liquid hydrogen per hour. Many thousands of liters of liquid parahydrogen were produced with the aid of this catalyst bed. So long as the catalyst was reactivated by heating and pumping $\left(104^{\circ} \mathrm{C}, 25 \mathrm{~mm} \mathrm{Hg}\right.$, for $24 \mathrm{hr}$ or more) whenever exposure to atmospheric air had 
occurred, there appeared to be no reduction in its effectiveness for bringing about the conversion to near equilibrium concentrations.

The results obtained with chromic oxide were gratifying, but a search for a more effective catalyst was continued in the hope of finding one that would occupy less space in the liquid reservoir. The large volume of chromic oxide catalyst required resulted in the formation of considerable quantities of dust or fines that could be carried through the system. To prevent this, filters and baffle plates had to be installed to prevent any shifting or motion of the catalyst pellets. This was probably the most serious difficulty overcome in the adaptation of chromic oxide on alumina to the NBS Cryogenic Engineering Laboratory liquefiers. Another disadvantage was the delay in initial cool-down resulting from the heat capacity of the large catalyst mass.

Since it was evident that the design of more compact parahydrogen liquefiers of various capacities would be simplified if a more efficient catalyst were available, a systematic study of materials that might catalyze the ortho-parahydrogen conversion was undertaken.

\section{Catalyst Survey}

The choice of materials to be tested was limited by such practical considerations as resistance to abrasion, availability, and economic feasibility. Beyond these considerations the selection of samples was based on the reports of previous investigators and on experience witb the chromic oxide on alumina. Taylor and Diamond [10] found definite correlation between catalytic effectiveness and both magnetic susceptibility and adsorptive capacity. Of interest also was the theory advanced by Wigner [11], which states that the velocity constant of the reaction is proportional to the square of the effective magnetic moment in Bohr magnetons.

The effective moment $\mu_{\text {eff }}$ is given by the relation

$$
\mu_{\mathrm{eff}}=2 \sqrt{S(S+1)}
$$

where $S$ represents total spin of the ion.

If $n$ is the number of unpaired electrons in the ion, then $S=n / 2$. Therefore, $\mu_{\text {eff }}=\sqrt{n(n+2)}$.

For chromic ion $\left(\mathrm{Cr}^{+3}\right)$ having three unpaired electrons $(n=3), \mu_{\text {eff }}=3.87$ magnetons, and for ferric ion $\left(\mathrm{Fe}^{+3}\right)$ having five unpaired electrons $(n=5)$, $\mu_{\text {eff }}=5.92$ magnetons.

Therefore, the ratio of the velocity constants according to Wigner's theory, should be

$$
\frac{(5.92)^{2}}{(3.87)^{2}}=2.34 \text {. }
$$

Accordingly, the ferric ion should be two and onethird times as effective for ortho-parahydrogen conversion as chromic ion, other things being equal.

\subsection{Catalyst Preparations}

With the above considerations in mind, 15 catalysts were obtained either commercially or prepared in the laboratory. A brief description of each material follows:

Paramagnetic ferric oxide $(15 \%)$ on Florex:

Fuller's earth granules obtained from the Floridin Co. were impregnated with a concentrated solution of ferrous ammonium nitrate. This was followed by heating the granules in a vacuum at $200^{\circ} \mathrm{C}$ for 48 hours. This technique for the preparation of supported ferric oxide free from ferromagnetism has been described by Selwood [12].

Paramagnetic ferric oxide $(2 \%)$ on porous glass:

Porous glass granules, obtained from the Corning Glass Works, were impregnated and oxidized as described above.

Magnetite $\left(\mathrm{Fe}_{3} \mathrm{O}_{4}\right)$ unsupported:

Granules of a synthetic magnetite were obtained from the U. S. Bureau of Mines. The granules were reduced in hydrogen at $450^{\circ} \mathrm{C}$, then oxidized in air at $490^{\circ} \mathrm{C}$.

Paramagnetic ferric oxide (15\%) and chromia $(9.3 \%)$ on alumina:

This mixed catalyst was prepared by impregnating pellets of $\mathrm{Cr}_{2} \mathrm{O}_{3}$ on Davison alumina with paramagnetic $\mathrm{Fe}_{2} \mathrm{O}_{3}$.

Ferric ammonium sulfate, unsupported:

This material was chosen because of its unusually high magnetic susceptibility at low temperatures.

Hydrous ferric oxide, unsupported:

The preparation of this material consisted of precipitation of the gel by addition of sodium hydroxide to a solution of ferric chloride, followed by washing the gel with distilled water. The gel was then filtered, extruded, dried, and activated in air at $140^{\circ} \mathrm{C}$.

Hydrous manganese oxide, unsupported:

The preparation here was the same as that for the hydrous ferric oxide, except that manganese chloride was substituted for the ferric chloride.

Manganese dioxide (18\%) on silica gel:

This material was prepared by addition of a solution of $\mathrm{Mn}\left(\mathrm{NO}_{3}\right)_{2}$ to a deactivated sample of Davison "Intermediate Density" silica gel. The granules were then dried and heated in a stream of air at $400^{\circ} \mathrm{C}$. This caused the nitrate to decompose, forming $\mathrm{MnO}_{2}$.

Ferrous chloride on silica gel:

Deactivated silica gel was impregnated with a water solution of ferrous chloride.

Nickel $(0.5 \%)$ on alumina:

This catalyst was obtained from Baker \& Co., Inc. Nickel $(5.3 \%)$ and thoria $(0.24 \%)$ on Davison alumina:

Since thoria is known to be a good promoter of nickel catalysts at high temperatures, this material was made by using a solution of 0.10 mole nickelous nitrate and 0.001 mole thorium nitrate in water. Alumina pellets were wetted with this solution, 
then dried and the nitrates decomposed to oxides in a stream of air at $400^{\circ} \mathrm{C}$. Finally, the nickel oxide distributed throughout the pellets was reduced to metallic nickel by treatment with hydrogen at $400^{\circ} \mathrm{C}$. Gadolinium oxide.

Neodymium oxide.

Crude cerium oxide:

These rare-earth oxides were tested because their successful use as ortho-parahydrogen conversion catalysts had been reported by Taylor and others. The oxides were tested in the form of unsupported powder.

Chromia $(20 \%)$ on alumina:

This was the Harshaw catalyst that had been used in the Cryogenic Engineering Laboratory liquefiers. It was used as a comparison in the evaluation of the other catalysts.

\subsection{Activities of Catalysts}

\section{a. Apparatus}

The apparatus constructed for the ortho-parahydrogen studies is shown schematically in figure 1 , and the analyzer is represented in figure 2 .

The analyzer was built around a thermal-conductivity cell and is described in a previous paper [13]. A reversing valve was, however, installed in the flow lines leading to the cell. This valve makes it possible to alternate the reference and analyzed gas streams from one side of the bridge to the other, thus obtaining an average reading from which a number of errors due to imperfect zero balance and filament matching have been eliminated. A four-way selector valve was also added to the analyzer as shown.

The central part of the apparatus shown in figure 1 is a stainless-steel Dewar enclosed in a sealed and vented metal container, which in turn is surrounded by a large liquid-nitrogen bath. The chamber that contained the catalyst being tested was a copper cylinder, 3/4-in. diameter by 4 in. long, suspended vertically from the top plate of the apparatus by

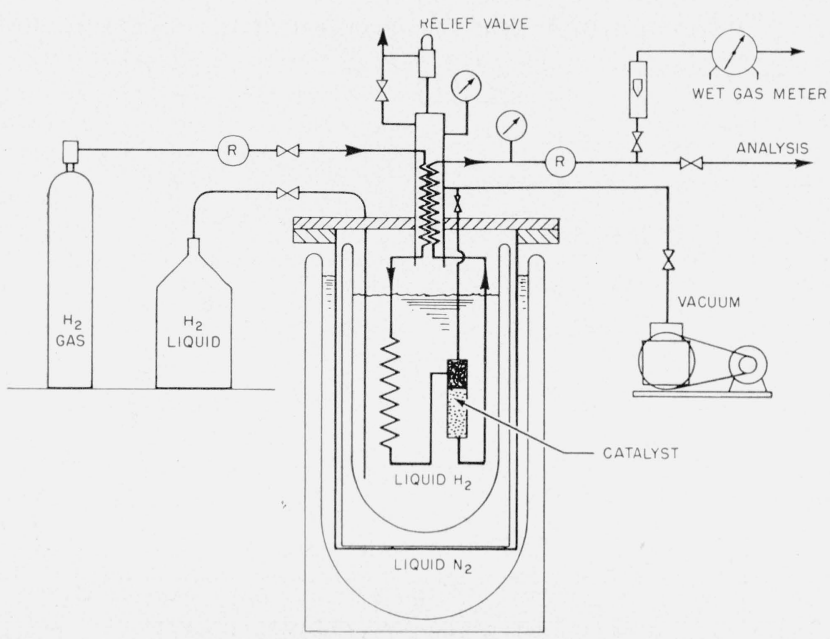

Figure 1. Catalyst evaluation apparatus.

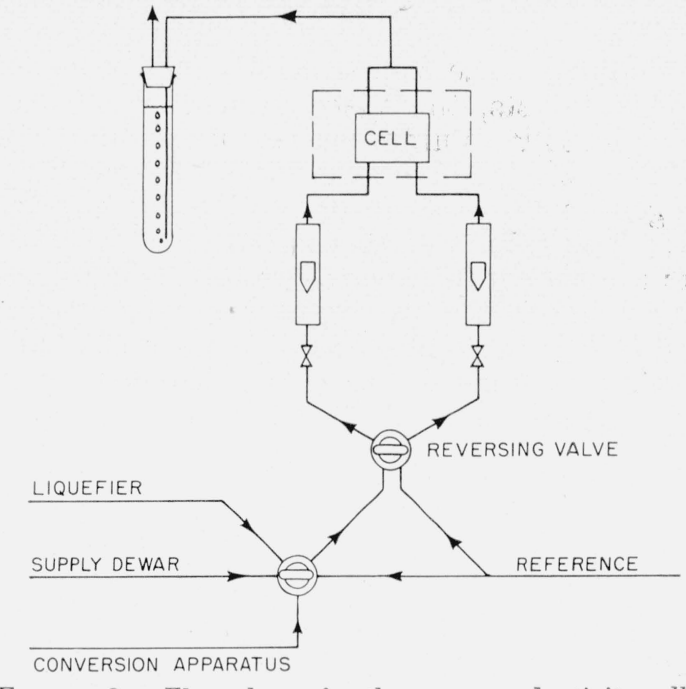

Figure 2. Flow sheet of ortho-para conductivity cell.

means of a stainless-steel tube, which also served as the pumping tap during catalyst cleanup. Hydrogen gas entering the chamber was first led through a heat exchanger, counter-current to the exhaust flow, then through a coil of copper tubing ( $1 / 8$ in.) in the bath liquid, and finally through the catalyst. The flow through the chamber was downward. The top inch of the chamber was packed with copper sponge to provide a volume of good heat exchange for recondensation of vapor formed by heat of conversion during liquid-phase studies. After passing through the catalyst, the hydrogen was warmed to room temperature, partly through heat exchange with the incoming gas and partly by passing through additional copper tubing after emerging from the Dewars. About $50 \mathrm{ml}$ per minute of the exhaust flow was deflected through the analyzer system, and the balance went through a rotameter and wet-gas meter before being vented to the atmosphere.

The catalyst temperature was assumed to be the same as that of the bath, and this could be varied by choice of bath liquid and by adjustment of the pressure under which the bath was maintained. For studying the catalyzed reconversion of para to normal hydrogen, the Dewars could be removed and a wire-wound sleeve heater controlled by a variable transformer placed around the catalyst chamber. This heater, together with the combined suspension tube and pumping tap mentioned above, served to reactivate the catalyst prior to a space-velocity measurement.

The same cylinder of purified normal hydrogen was used to provide reference gas for the analysis cell and gas to be converted in the catalyst chamber. Calibration of the analysis system at 99.8 percent parahydrogen was conveniently obtained at the beginning of a run simply by using the exhaust gas from the catalyst chamber at two different (low) flow rates, both of which gave the same analysis signal. Calibration at 25 percent parahydrogen resulted from passing the normal reference hydrogen simultaneously through both sides of the analysis cell. 


\section{b. Results}

To determine the comparative effectiveness of the various catalysts, the space velocity was measured for each in STP volumes per minute per unit volume of catalyst when converting normal 25 percent parahydrogen to 90 percent para with the catalyst at $20^{\circ} \mathrm{K}$. The results of this initial series of measurements are shown in table 1 , where the catalysts are arranged according to increasing space velocities. Also shown is the relative effectiveness of each catalyst when compared with the Harshaw chromic oxide on alumina.

TABLE 1. Conversion of 25-percent para to 90-percent para at $20^{\circ} \mathrm{K}, 15 \mathrm{psig}$

\begin{tabular}{|c|c|c|}
\hline Catalyst & $\begin{array}{c}\text { Space } \\
\text { velocity }\end{array}$ & $\begin{array}{c}\text { Relative } \\
\text { space } \\
\text { velocity } \\
\left(\mathrm{Cr}_{2} \mathrm{O}_{3}=1\right)\end{array}$ \\
\hline Gadolinium oxide, unsupported_.- & $\underset{10}{S T P / \min }$ & \\
\hline Crude ceric oxide, unsupported... & 20 & .4 \\
\hline Neodymium oxide, unsupported. & 20 & 4 \\
\hline $\mathrm{FeCl}_{2}$ on silica gel & 20 & 4 \\
\hline $2 \%$ paramagnetic $\mathrm{Fe}_{2} \mathrm{O}_{3}$ on porous glass & 20 & .4 \\
\hline $15 \%$ paramagnetic $\mathrm{Fe}_{2} \mathrm{O}_{3}$ on Florex & 24 & .5 \\
\hline Ferric ammonium sulfate, unsupported & 30 & 6 \\
\hline Magnetite, $\mathrm{Fe}_{3} \mathrm{O}_{4}$, unsupported & 40 & .8 \\
\hline $20 \% \mathrm{Cr}_{2} \mathrm{O}_{3}$ on alumina (Harshaw) & 50 & 1.0 \\
\hline $\begin{array}{l}15 \% \text { paramagnetic } \mathrm{Fe}_{2} \mathrm{O}_{3} \text { and } 9.3 \% \quad \mathrm{Cr}_{2} \mathrm{O}_{3} \text { on } \\
\text { alumina }\end{array}$ & 50 & 1.0 \\
\hline $5.3 \% \mathrm{Ni}$ and $0.24 \%$ thoria on alumina & 60 & 1.2 \\
\hline $18 \% \mathrm{MnO}_{2}$ on silica gel & 80 & 1.6 \\
\hline $0.5 \% \mathrm{Ni}$ on alumina & 100 & 2.0 \\
\hline Hydrous manganese dioxide, unsupported...... & 190 & 3.8 \\
\hline Hydrous ferric oxide, unsupported & 330 & 6.6 \\
\hline
\end{tabular}

The rare-earth oxides did not show up very well, being less than half as active as chromic oxide on alumina. (It is difficult to compare these results with the work of Taylor and Diamond [6] because no actual space velocities are reported in their article.) In the present investigation, the laboratory preparations of iron oxide free from ferromagnetism were hardly as good as the reference chromic oxide on alumina. The high magnetic susceptibility of ferric ammonium sulfate at the temperature of the conversion did not result in an outstanding catalyst, but gave an activity between those of paramagnetic iron oxide on Florex and unsupported synthetic magnetite. The nickel and manganese compounds resulted in good catalysts, with $1 / 2$ percent nickel on alumina twice as good and manganese dioxide on silica gel 1.6 times as good as the reference chromic oxide on alumina.

Although attempts to reduce ferromagnetism of supported iron oxide catalysts did not help the catalytic effectiveness, there was a marked improvement in both manganese and iron when the supported oxide was replaced by the unsupported hydrous form. Thus hydrous manganese oxide was about four times and hydrous iron oxide almost seven times as good as chromic oxide on alumina.

\section{Hydrous Iron Oxide Catalyst}

\subsection{Laboratory Studies}

Additional measurements with the hydrous iron oxide disclosed at once that the space velocity for liquid-phase conversion could be further increased by a very significant factor simply by using a smaller particle size. The original measurements had been made with approximately $1 / 8-i n$. pellets. Cutting each of these into about four pieces increased the space velocity from 330 to 750 , and grinding the material into a fine powder resulted in a STP space velocity of almost 2,000 per minute.

Since there are obvious disadvantages to the use of fine powders in liquefiers, it was desirable to prepare more of the material in order to experıment with various mesh sizes and particle modifications. Difficulties were encountered, some of which are referred to by Weiser [14], i. e., properties of the hydrous oxides may show marked variations with small variations in treatment of the sample. Although reasonable care was taken to use the same procedure in the preparation of several samples, the space velocities of the resultant products would vary, sometimes by a factor of 2 or 3 . It was necessary to prepare a number of batches before sufficient high-activity material was collected to support the research and charge one of the large Cryogenic Engineering Laboratory liquefiers.

The reasons for the increased activity of the better preparations were not entirely clear. No correlation was found, for example, between catalytic activity and the concentration of various metallic impurities as determined by spectrographic analysis. Increased bulk density was identified with increased catalytic activity, but the procedure for obtaining a high-density product was not apparent. Of course, some increased activity of the unsupported oxide should be anticipated because of the higher percentage of iron in the sample. This is certainly an over simplification and would not explain the range in catalytic activities of the other iron preparations.

An excellent correlation was found between catalytic activity and surface area as determined from low-temperature nitrogen adsorption by application of the Brunauer, Emmett, and Teller theory [15]. The surface areas of three laboratory preparations of 30 to 100 mesh hydrous iron oxide are shown in figure 3 plotted against their corresponding catalytic ac-

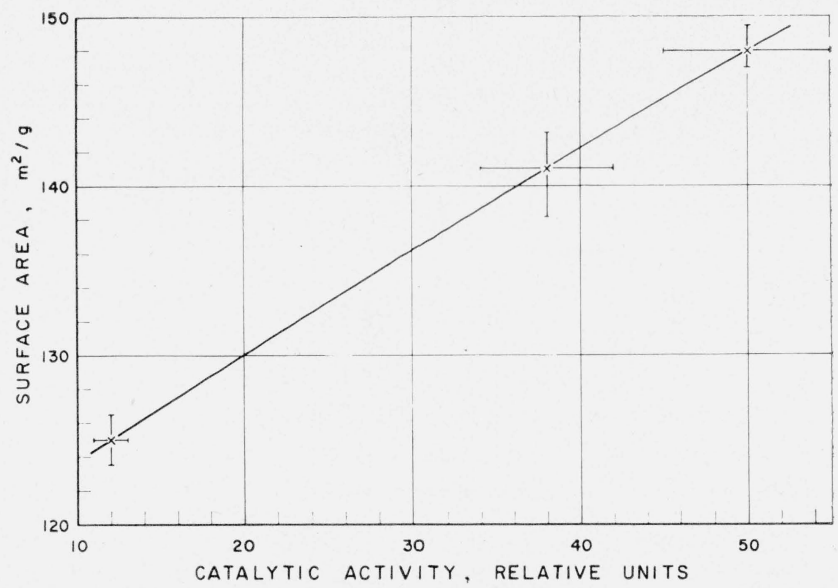

Figure 3. Correlation of catalytic activity with surface area. 
tivities relative to the reference chromia catalyst. The crosses passing through each point correspond to the confidence limits of the measurements. It is apparent that the degree of correlation is striking within the range studied. The factors that affect the surface area of the ultimate catalyst have not been thoroughly investigated, but it is felt that variations in the degree and extent of heating during formation and/or activation are of prime importance in this regard.

Selwood [12] described in considerable detail the preparation of iron oxide free from ferromagnetism. When Selwood's directions were not followed, as in the preparation of unsupported hydrous ferric oxide, appreciable ferromagnetism was introduced. ${ }^{3}$ Yet, these were the very samples that exhibited the highest catalytic activity. Admittedly, very little is known regarding the effect of ferromagnetism on catalytic activity. In discussing the applicability of ferromagnetic studies to catalyst structure problems, Selwood [12] states, "Ferromagnetism, in contrast to paramagnetism, is a cooperative phenomenon. A substance does not become ferromagnetic until the grain size exceeds a certain critical size, sometimes referred to as the ferromagnetic domain. This is a situation which somewhat weakens the applicability of ferromagnetic studies to catalyst structure problems. Those particles which are too finely divided to show ferromagnetism are precisely those which are likely to exhibit the most catalytic activity. This is true by virtue of their large surface area, if for no other reason." From the results of the present work, the influence of ferromagnetism might, indeed, have enhanced the activity of the catalyst. As stated previously, only $2 \frac{1}{3}$-fold increase in activity of iron over chromium was to be expected, based on paramagnetic considerations. The actual improvement realized was many fold greater than this.

The results of the particle-size investigation are interesting. For liquid-phase conversion granules of 20 to 30 mesh proved almost twice as effective as 10 to 20 mesh, but 40 to 50 mesh was very little better than 20 to 30 mesh. Tests of particles smaller than 50 mesh showed very little further improvement. For vapor-phase conversion at $76^{\circ} \mathrm{K}$ the situation was somewhat different. Here the gain in going from 10 to 20 mesh to 40 to 50 mesh was only about 15 percent, and again beyond 50 mesh there was little or no further improvement.

The space velocities for ortho-para conversion in the presence of these hydrous iron oxide granules are so high that very small samples of catalyst, usually $7 \mathrm{ml}$, were used for making the measurements. This was necessary to avoid having complete conversion at all but excessively high flow rates. The smaller samples also made possible a considerable simplification of the apparatus, as shown in figure 4 . The catalyst was merely placed in a slim capsule with $1 / 8$-in.-diameter inlet and outlet lines and dropped through the neck of a standard 50-liter

\footnotetext{
r ${ }^{3}$ It was possible to pick up particles of this catalyst preparation by means of a small permanent magnet.
}

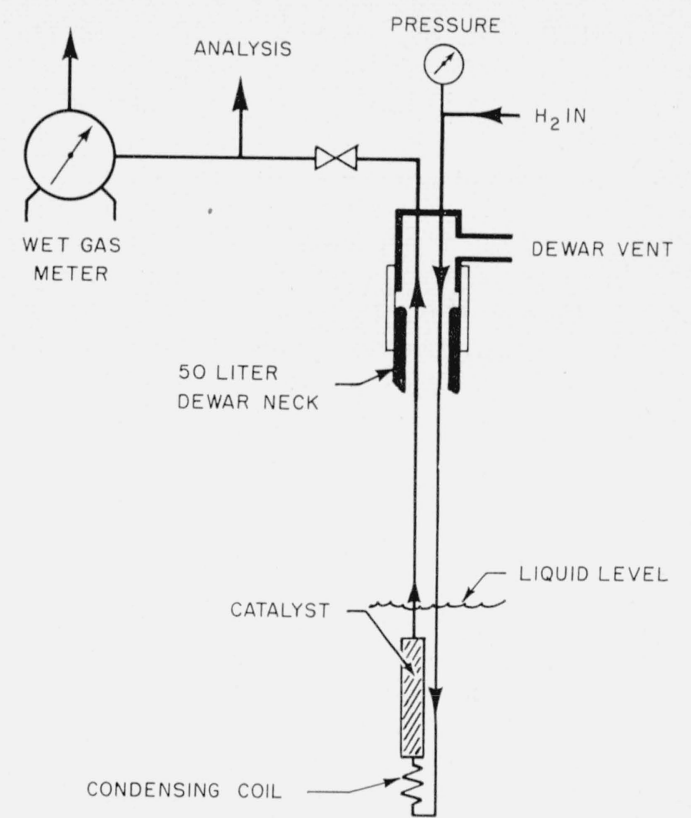

Figure 4. Ortho-para catalyst testing capsule.

liquid-hydrogen Dewar. Space velocities for conversion of 25 to 90 percent para, measured in this way, had STP values between 2,000 and 2,500 per minute for liquid-phase conversion when using granules of 20 mesh or smaller. In terms of liquidhydrogen production, this means 1 liter of catalyst placed in the liquid receiver will convert 150 to 190 liters of liquid per hour from 25 to 90 percent para.

\subsection{Hydrous Iron Oxide in CEL Liquefiers}

The hydrous iron oxide catalyst has been used for liquid-phase conversion in two small and one large liquefier at the NBS Cryogenic Engineering Laboratory and has performed at least as well as predicted by the laboratory-scale space-velocity measurements. In the small liquefiers the catalyst was placed between screens in such a way that liquid head building up outside the catalyst container provided sufficient force to push liquid up through the bed from bottom to top. This was found to be more satisfactory than simply discharging the unconverted liquid on top of the catalyst and attempting to withdraw it from the bottom of the bed. The difficulty in the latter approach arises because returning vapor, caused by heat of conversion, forms a barrier that effectively prevents downward flow of liquid. The liquid therefore builds up on the catalyst until it spills over the top of the container. With the former arrangement, however, one liquefier, using $370 \mathrm{ml}$ of 30 - to 40 -mesh catalyst, produced 40 liters per hour of 90 percent para, and another using $1,200 \mathrm{ml}$ of 10 - to 20 -mesh produced 80 liters per hour of 95 percent para. The realized space velocity is, in the first instance, a little less than was predicted on the basis of laboratory measurements, whereas in the second case the catalyst performed somewhat better than predicted 
For installation of the new catalyst in the large liquefier a novel split-flow arrangement designed by V. J. Johnson and P. C. Vander Arend was employed [16]. The system, as illustrated in figure 5, involves a second Joule-Thomson expansion valve connected directly to an assembly made up of the catalyst container, preceded and followed by adequate heat-exchanger surface. The catalyst container and heat exchangers are immersed in liquid supplied through the usual Joule-Thomson expansion valve. After passing through this condensationconversion-recondensation train, the entire steam goes directly to the liquid-transfer siphon. Thus, unconverted liquid is used as refrigerant to condense totally and to remove heat of conversion from the stream of converted liquid that is delivered to the storage vessel.

The results of three trial runs with this arrangement and 1.5 liters of 30- to 100-mesh hydrous iron oxide catalyst were reported by Johnson [16]. At that time about 4,500 liters of liquid had been made, and the quantity of catalyst, as well as the area of heat-exchanger surface, appeared to be borderline. Since these initial runs, however, the catalyst has received more consistent cleanup treatment, and experience has been gained in operation of the split-flow double-valve arrangement. Although no changes in catalyst or heat exchangers have been made, there has been a significant improvement in performance. An additional 100,000 liters of liquid has since been produced. Most of this has passed through the catalyst at 230 to 240 liters of liquid per hour. This represents a liquid space velocity of about 2.6 per minute, or an STP space velocity of a little more than 2,000 per minute. Space velocity measured in the laboratory for a small sample of this batch of catalyst gave 2,200 STP per minute for conversion from 25 to 90 percent para.

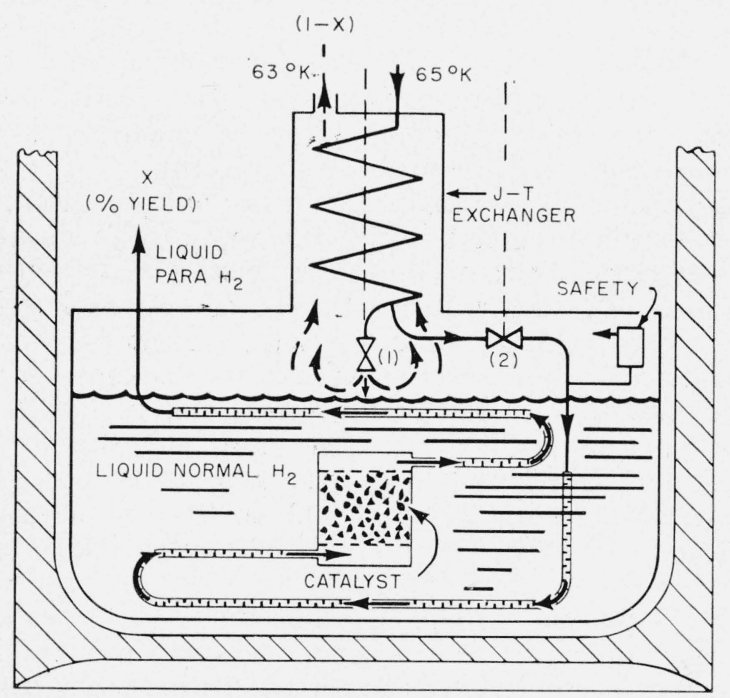

FIgURE 5. Installationof hydrous iron oxide catalyst in large Cryogenic Engineering Laboratory liquefier.

\subsection{Catalyst Activation and Lifetime}

After initial drying and activation of the catalyst in air at temperatures up to $140^{\circ} \mathrm{C}$, the normal activation procedure has been to maintain the hydrous iron oxide granules at reduced pressure and moderate temperature for at least $16 \mathrm{hr}$. In the laboratory, evacuation has been to the order of $1 \mathrm{~mm}$ $\mathrm{Hg}$ or less at $110^{\circ}$ to $120^{\circ} \mathrm{C}$. These conditions are maintained immediately prior to an activity test, and the vacuum is broken with pure hydrogen gas. The catalyst changes its structure and is completely ruined if heated much beyond $140^{\circ} \mathrm{C}$.

In one test it was found that a few days of exposure to atmospheric air reduced the effectiveness to onethird of its normal value. In another test a cleanup of $6 \mathrm{hr}$ resulted in a space velocity of 1,800 per minute, whereas a 3-day cleanup raised this to 2,600 per minute. The behavior indicated by these laboratory tests is also borne out in the large liquefier. For example, power failure prior to one liquefaction run resulted in a cleanup of only $3 \mathrm{hr}$ at the specified temperature. This run produced 80 to 85 percent parahydrogen. Subsequent runs with the same catalyst and a 16-hr cleanup resulted in 90 to 95 percent parahydrogen at equal or higher production rates.

In an effort to obtain data on the probable lifetime of the catalyst, a sample was cycled in the laboratory between use at $20^{\circ} \mathrm{K}$ and activation at $110^{\circ} \mathrm{C}$. The sample was subjected to a total of 31 cycles over a period of 6 weeks. The total time in use for conversion was $137 \mathrm{hr}$, and the total time on activation was $821 \mathrm{hr}$. The conversion activity remained essentially constant throughout, being actually a little higher at the end than at the beginning of the tests. Plant-scale data on catalyst lifetime consists at present of production of about 100,000 liters of converted liquid over a period of about 5 months. The hydrous ferric oxide catalyst (1.5 liters of 30 to 100 mesh) being used shows no sign of decreasing activity.

The authors express appreciation to Frank E. E. Germann for literature survey and for writing the introduction to this paper. K. D. Timmerhaus has followed the course of much of the work and offered valuabl s suggestions. C. C. Van Valin has contributed by making many of the more recent spacevelocity measurements. L. E. White ${ }^{4}$ was in charge of the group when the catalyst survey program was initiated. Also, we acknowledge and appreciate the contribution of the gas liquefaction group of CEL, particularly V. J. Johnson, W. A. Wilson, and J. E. Jensen, who installed and tested the iron catalyst in various liquefiers. Finally, thanks are due P. C. Vander Arend $^{5}$ for guidance and encouragement over a period of several years, during which the ortho-parahydrogen program experienced a number of changes of fortune.

${ }^{4}$ Presently associated with ${ }^{-}$A erojet General Corporation.

5 Presently associated with Air Products, Inc. 


\section{References}

[1] H. W. Wooley, R. B. Scott, and F. G. Brickwedde J. Research NBS 41, 379 (1948) RP1932.

[2] L. Farkas and H. Sachsse, Z. Physik. Chem. B23, 1 and 19 (1933).

[3] K. F. Bonhoeffer and P. Harteck, Naturwiss. 1\%, 182 (1929).

[4] A. Farkas, Orthohydrogen, parahydrogen, and heavy hydrogen (Cambridge University Press, p. 89, 1935).

[5] H. S. Taylor and A. Sherman, J. Am. Chem. Soc. 53, 1614 (1931).

[6] H. S. Taylor and H. Diamond, J. Am. Chem. Soc. 55, 2613 (1933).

[7] P. H. Emmett and R. W. Harkness, J. Am. Chem. Soc. 5\%, 1624 and 1631 (1935).

[8] E. R. Grilly, Rev. Sci. Instr. 24, 1 (1953); $\mathbf{2 4 ,} 899$ (1953).

[9] L. E. White, P. C. Vander Arend, and P. L. Barrick (unpublished report).
[10] H. S. Taylor and H. Diamond, J. Am. Chem. Soc. 5\%, 1251 (1935).

[11] E. Wigner, Z. Physik. Chem. B19, 203 (1932); B23, 28 (1933).

[12] P. W. Selwood, Advances in catalysis, III, p. 80-85 (Academic Press, Inc., New York, N. Y., 1951).

[13] D. H. Weitzel and L. E. White, Rev. Sci. Instr. 26, 290 (1955).

[14] H. B. Weiser, Inorganic colloid chemistry, VII. The hydrous oxides and hydroxides, p. 27, $31 \mathrm{ff}$, (John Wiley \& Sons, Inc., New York, N. Y., 1935).

[15] S. Brunauer, P. H. Emmett, and E. Teller, J. Am. Chem. Soc. 60, 309 (1938).

[16] Proceedings of 1956 Cryogenic Engineering Conference held at NBS in Boulder, Colo., Paper A-4 (September 1956).

Boulder, Colo., October 7, 1957. 